Introduction/Background* Implementation of NGS panel sequencing (instead of single/double gene/s sequencing) into standard genetic testing for cancer susceptibility generates new and unexpected data on spectrum, proportion and combination of susceptibility genes' mutations.

Methodology We analyzed results of genetic testing in healthy patients referred to our survailance office, their pedigrees and clinical manifestations to identify and describe clinical meaning of combined heterozygosity in different cancer suceptibility genes. We also discusse prophylactic measures in these double heterozygotes.

Result(s)* In the group of 455 individuals who underwent genetic testing for known or suspicious genetic susceptibility to cancer, we identify $11(2.4 \%)$ double heterozygotes, i.e. individual harbouring germ-line pathologic mutations in two high penetrance susceptiblity genes. 8 of them have mutations in either BRCA1/2 genes and mismatch-repair genes (MLH1 or MSH2), 3 remaining have combination of BRCA1 mutation and RAD51, VHL and CHEK2, respectivelly. 3 out of 11 double heterozygotes developer cancer through median followup of 34 moths, 2 breast cancer, 1 colorectal cancer. Pedigree analysis does not allow for individualisation of risk calculation.

Conclusion* Double heterozygotes are known from literature, till the era of NGS panel sequencing, they wer thought to be extremelly rare. These individuals, however, represent a substantional proportion of our patients and need individualised scenario of survailance with respect to different spectrum of risks compared to single mutation carriers.

\section{UPTAKE OF POPULATION BASED BRCA-TESTING ACROSS JEWISH DENOMINATIONS AND AFFECT OF CULTURAL AND RELIGIOUS FACTORS: A COHORT STUDY}

${ }^{1} \mathrm{D}$ Reisel, ${ }^{2} \mathrm{M}$ Burnell, ${ }^{3} \mathrm{~L}$ Side, ${ }^{1} \mathrm{~K}$ Loggenberg, ${ }^{1} \mathrm{~S}$ Gessler, ${ }^{1} \mathrm{R}$ Desai, ${ }^{4} \mathrm{~S}$ Sanderson, ${ }^{5} \mathrm{~A}$ Brady, ${ }^{6} \mathrm{H}$ Dorkins, ${ }^{7} \mathrm{Y}$ Wallis, ${ }^{8} \mathrm{C}$ Jacobs, ${ }^{9} \mathrm{R}$ Legood, ${ }^{10} \mathrm{U}$ Beller, ${ }^{11} \mid \mathrm{I}$ Tomlinson, ${ }^{2} \mathrm{U}$ Menon, ${ }^{12}$ Jacobs, ${ }^{9,13} \mathrm{R}$ Manchanda*. 'University College London, Institute for Women's Health, UK; ${ }^{2}$ University College London, MRC Clinical Trials Unit, London, UK; ${ }^{3}$ University Hospital Southampton NHS Foundation Trust, Clinical Genetics, UK; ${ }^{4}$ University College London, Behavioral Sciences Unit, Dept Epidemiology and Public Health, London, UK; ${ }^{5}$ Northwick Park Hospital, North West Thames Regional Genetics Service, UK; ${ }^{6}$ University of Oxford, St Peter's College, UK; ' Birmingham Women's Hospital, West Midlands Regional Genetics Laboratory, UK; ${ }^{8}$ University of Technology Sydney, Ultimo, Australia; ${ }^{9}$ London School of Hygiene and Tropical Medicine, Health Services Research and Policy, London, UK; ${ }^{10}$ Shaare Zedek Medical Center, Jerusalem, Israel; ${ }^{11}$ University of Birmingham, UK; ${ }^{12}$ UNSW Sydney, Sydney, Australia; ${ }^{13}$ Queen Mary University of London, Centre for Cancer Prevention, London, UK

\subsection{6/ijgc-2021-ESG0.557}

Introduction/Background* Population-based BRCA-testing in the Ashkenazi Jewish (AJ) population is feasible, acceptable, reduces anxiety, identifies more BRCA-carriers and is costeffective. The Jewish population is the first population for whom unselected population testing is now being implemented with Israel recently adopted this into national policy. Guideline change is being advocated in the UK and by others too. It is unknown whether BRCA-testing differs across Jewish denominational affiliations and religious or cultural outlook. We evaluate the association of Jewish cultural and religious identity and denominational affiliation with interest-in, intention-to undertake and uptake-of population-based BRCAtesting

Methodology
Design Cohort-study set within recruitment to GCaPPS-trial (ISRCTN73338115).

AJ men and women, >18years, from London, self-referred, and attended recruitment clinics(clusters) for pre-test counselling. Subsequently consenting individuals underwent BRCAtesting. Mina oucome measures were: Interest, intention, uptake-of BRCA-testing. Participants self-identified to one Jewish denomination: Conservative/Liberal/Reform/Traditional/ Orthodox/Unaffiliated. Validated scales measured Jewish Cultural-Identity (JI) and Jewish Religious-identity (JR). 4-item Likert-scales analysed initial 'interest' and 'intention-to-test' pre-counselling. Item-Response-Theory and graded-responsemodels, modelled responses to JI and JR scales. Ordered/multinomial logistic regression modelling evaluated association of JI-scale, JR-scale and Jewish Denominational affiliation on interest, intention and uptake-of BRCA-testing.

Result(s)* 935 AJ women/men of mean-age=53.8 (S.D=15.02) years, received pre-test education and counselling through 256 recruitment clinic clusters (mean cluster size $=3.64$ ). Denominational affiliations included Conservative/Masorti=91(10.2\%); Liberal $=82(9.2 \%), \quad$ Reform $=135(15.1 \%), \quad$ Traditional $=212$ $(23.7 \%)$, Orthodox $=239(26.7 \%)$; and Unaffiliated/Non-practising $=135(15.1 \%)$. Overall BRCA-testing uptake was $88 \%$. Precounselling 96\% expressed interest and 60\% intention-to test. JI and JR scores were highest for Orthodox, followed by Conservative/Masorti, Traditional, Reform, Liberal and Unaffiliated Jewish denominations. Regression modelling showed no significant association between overall Jewish Cultural or Religious Identity with either interest, intention or uptake-of BRCA-testing. Interest, intention and uptake of BRCA-testing was not significantly associated with denominational affiliation. Conclusion* Jewish religious/cultural identity and denominational affiliation do not appear to influence interest, intention or uptake of population-based BRCA-testing. BRCA-testing was robust across all Jewish denominations.

\section{RISK-REDUCING SURGERY IN BRCA MUTATION: A MULTICENTRIC PROSPECTIVE STUDY}

V Loizzi* , F Arezzo, CM Santarsiero, V Cataldi, C Putino, I Romagno, G Cazzato, G Serio, L Resta, E Cicinelli, G Cormio. University of Bari Aldo Moro, Bari, Italy

\subsection{6/ijgc-2021-ESG0.558}

Introduction/Background* BRCA1/2 are tumour-suppressor genes involved in DNA homologous recombination and ovarian cancer development.

Methodology Risk-reducing surgery (RRS) was performed in 148 patients carrying BRCA1 (aged between 30-73 years, median age was 51 years) and BRCA 2 mutation (aged between $36-70$ years, median age was 53 years). Seventy-nine patients had previous history of breast cancer.

Result(s)* Between the all patients, 131 women underwent risk-reducing salpingo-oophorectomy (RRSO) through a laparoscopic minimally invasive approach, $11(7,4 \%)$ underwent laparoscopic RRSO and contextual hysterectomy, 2 woman $(1,3 \%)$ underwent RRSO through a laparotomic approach and 12 women $(8,1 \%)$ laparotomic RRSO and hysterectomy. During 7 (4,7\%) laparoscopic RRSO, prophylactic bilateral mastectomy was also performed.

Conclusion* RRSO is safe and feasible in BRCA mutation carriers. The procedure is effective for genetic prevention of ovarian cancer. 